\title{
Spec3: embryonic expression of a sea urchin gene whose product is involved in ectodermal ciliogenesis
}

\author{
Elizabeth D. Eldon, ${ }^{1,2}$ Lynne M. Angerer, ${ }^{3}$ Robert C. Angerer, ${ }^{3}$ and William H. Klein ${ }^{1}$ \\ 'Department of Biochemistry and Molecular Biology, The University of Texas, M.D. Anderson Hospital and Tumor Institute, \\ Houston, Texas 77030 USA; ${ }^{2}$ Program in Molecular, Cellular, and Developmental Biology, Indiana University, Bloomington, \\ Indiana $47405 \mathrm{USA}^{3}{ }^{3}$ Department of Biology, University of Rochester, Rochester, New York USA 14627 USA
}

\begin{abstract}
We have characterized the temporal and spatial expression of Spec 3 mRNA in embryos of the sea urchin, Strongylocentrotus purpuratus. This mRNA, $2.0 \mathrm{~kb}$ in length, is present at low levels in unfertilized eggs but accumulates rapidly during cleavage, increasing 50 -fold by hatching blastula stage. Message levels then decline abruptly, remain constant during mesenchyme blastula and gastrula stages, and increase again during prism and pluteus stages. This accumulation pattern is quite similar to that of the ectodermally expressed $\beta$-tubulin mRNAs described recently by Harlow and Nemer (1987a). In situ hybridization shows that although Spec3 message accumulates in all blastomeres at early blastula stages, it later becomes restricted to ectoderm. By late blastula stage, hybridization is strongest in the animal hemisphere. At gastrula, signals are variable over ectoderm, and by pluteus, grains are concentrated in the ciliary band, though present in other ectodermal cells as well. Deciliation and regeneration of cilia in gastrula-stage embryos results in a four- to fivefold increase in Spec3 mRNA levels, implying that the Spec 3 gene product is associated with ciliogenesis. Spec3 mRNA is encoded by a single gene in the haploid genome, and characterization of the gene shows that it contains three exons that encode an open reading frame for a hydrophobic protein of $21.6 \mathrm{kD}$. The reading frame reveals that the carboxy-terminal part of the protein contains two long hydrophobic stretches, 31 and 37 residues long, separated by short hydrophilic regions of six to eight residues. The presence of these two distinct hydrophobic stretches suggests that the Spec 3 protein contains two $\alpha$-helical domains that either span the lipid bilayer or are associated with some other hydrophobic environment.
\end{abstract}

[Key Words: Sea urchin embryo; embryonic ectoderm; ciliogenesis; in situ hybridization; hydrophobic protein] Received August 3, 1987; revised version accepted October 6, 1987.

In recent years much information has been gained by utilizing cell type- or region-specific DNA clones and antibodies to study sea urchin embryogenesis. An impressive variety of molecular probes has been used in a number of investigations, including ones that have identified the origins and fates of several embryonic cell lineages (Lynn et al. 1983; Gibson and Burke 1985; Cox et al. 1986; Pehrson and Cohen 1986), studied the effects of embryonic perturbations on determination and differentation (Nemer 1986; Wessel and McClay 1987), and identified novel proteins associated with either the differentiation of embryonic cell types (Carpenter et al. 1984; Wessel and McClay 1985; Leaf et al. 1987) or the generation of embryonic structures (Wessel et al. 1984; Benson et al. 1987).

Here we describe an mRNA from Strongylocentrotus purpuratus embryos, Spec 3 (Spec is an abbreviation for $S$. purpuratus ectoderm), with an unusual temporal and spatial accumulation pattern. The regulation of Spec3 gene expression suggests it is associated with ciliogenesis. A cDNA clone specifying the ectodermally restricted Spec3 mRNA was originally isolated from a dif- ferential screen of a pluteus cDNA library, using radiolabeled probes derived from pluteus ectoderm vs. endoderm/mesoderm fractions (Bruskin et al. 1981). Here we show that the Spec3 message is one of the earliest transcripts known to accumulate in the embryo and that its pattern of expression correlates both with the expression of ectodermal $\beta$-tubulin messages and with the formation of cilia on ectodermal cells during embryogenesis. We also show that the Spec3 message is encoded by a single gene whose putative protein product has a previously undescribed sequence with high proline content in the amino terminus and long hydrophobic stretches in the carboxyl terminus.

\section{Results}

Accumulation of the Spec3 transcript during embryogenesis

Our previous report (Bruskin et al. 1981) indicated that Spec3 transcripts are $2.2 \mathrm{~kb}$ long $^{1}$ and accumulate earlier

${ }^{1} A$ more accurate estimate of the transcript length using RNA makers shows the transcript to be $2.0 \mathrm{~kb}$ long. 
in embryogenesis than had been reported for any other cloned gene, with the exception of the $\alpha$-histone genes (Maxson and Wilt 1982). Although Spec3 was selected because it is enriched in ectoderm cells of plutei, maximal accumulation of Spec3 message occurs long before the morphological differentiation of any ectodermal cell types.

To obtain a detailed picture of Spec3 transcript accumulation, we isolated total embryo RNA either at 4-hr intervals (unfertilized egg through prism stage) or 6-hr intervals (prism through pluteus stage) and analyzed it by RNA blotting. A portion of the Spec 3 cDNA containing the entire open reading frame and small regions of $5^{\prime}$ and $3^{\prime}$ untranslated sequences was subcloned and used as a single-stranded hybridization probe. Multiple exposures of the autoradiogram were scanned densitometrically to quantify relative mRNA abundance (Fig. 1). As demonstrated in our earlier study, Spec3 transcripts are present at very low levels in the egg (Bruskin et al. 1981) and do not increase in abundance through the first four or five cleavages $(6-7 \mathrm{hr})$. Levels then increase dramatically: threefold by morula stage $(11 \mathrm{hr})$ and 50 - fold by hatched blastula stage $(20 \mathrm{hr})$. The transcript levels then decrease rapidly by gastrula stage to about one-fourth of their maximal levels. Spec3 mRNA accumulates again in prism and pluteus stages, though never to hatched blastula levels. These data indicate that Spec3 mRNA accumulates during embryogenesis in a biphasic manner, with a major peak of accumulation around hatched bastula stage and a minor peak around pluteus stage.

We found evidence for variation in the level of Spec3 in different egg batches. The experiment shown in
Figure 1 was carried out with a pool of eggs from several females, but similar analyses were carried out to $50 \mathrm{hr}$ of development on two other occasions with different pools of eggs. In each case, hybridization signals were normalized for RNA loads using a probe for mitochondrial $16 \mathrm{~S}$ rRNA, whose concentration does not change during embryogenesis (Wells et al. 1982). Although all three experiments showed the same rapid accumulation of blastula stage, there were significant differences, ranging from $10 \%$ to $50 \%$ of the maximal level, in the amount of message present between 25 and $50 \mathrm{hr}$.

Alexandraki and Ruderman (1985) showed that in $L y$ techinus pictus, RNA blots utilizing probes for both $\alpha$ and $\beta$-tubulin mRNAs produced accumulation patterns similar to that seen for Spec3 transcripts in $S$. purpuratus. Recently, $\beta$-tubulin messages from $S$. purpuratus have been characterized by Harlow and Nemer (1987a). Using a probe from the $3^{\prime}$ untranslated region specific for the $\beta_{1}$-tubulin RNA, they found that this message was highly enriched in ectodermal tissue. The inset in Figure 1 shows the temporal pattern of $\beta_{1}$-tubulin mRNA expression redrawn from the data of Harlow and Nemer (1987a). The accumulation of this message and of two other moderately ectoderm-specific tubulins, $\beta_{2}$ and $\beta_{3}$, bears a striking resemblance to Spec3 message accumulation.

Several lines of evidence indicate that the Spec3 transcript encodes a protein product. First, a nearly fulllength cDNA clone was isolated from a library constructed from oligo(dT)-primed polysomal poly(A) RNA. Second, we have identified a 208-codon open reading frame that can be translated in vitro /see below and Eldon 1988). Third, hybridization analysis shows that

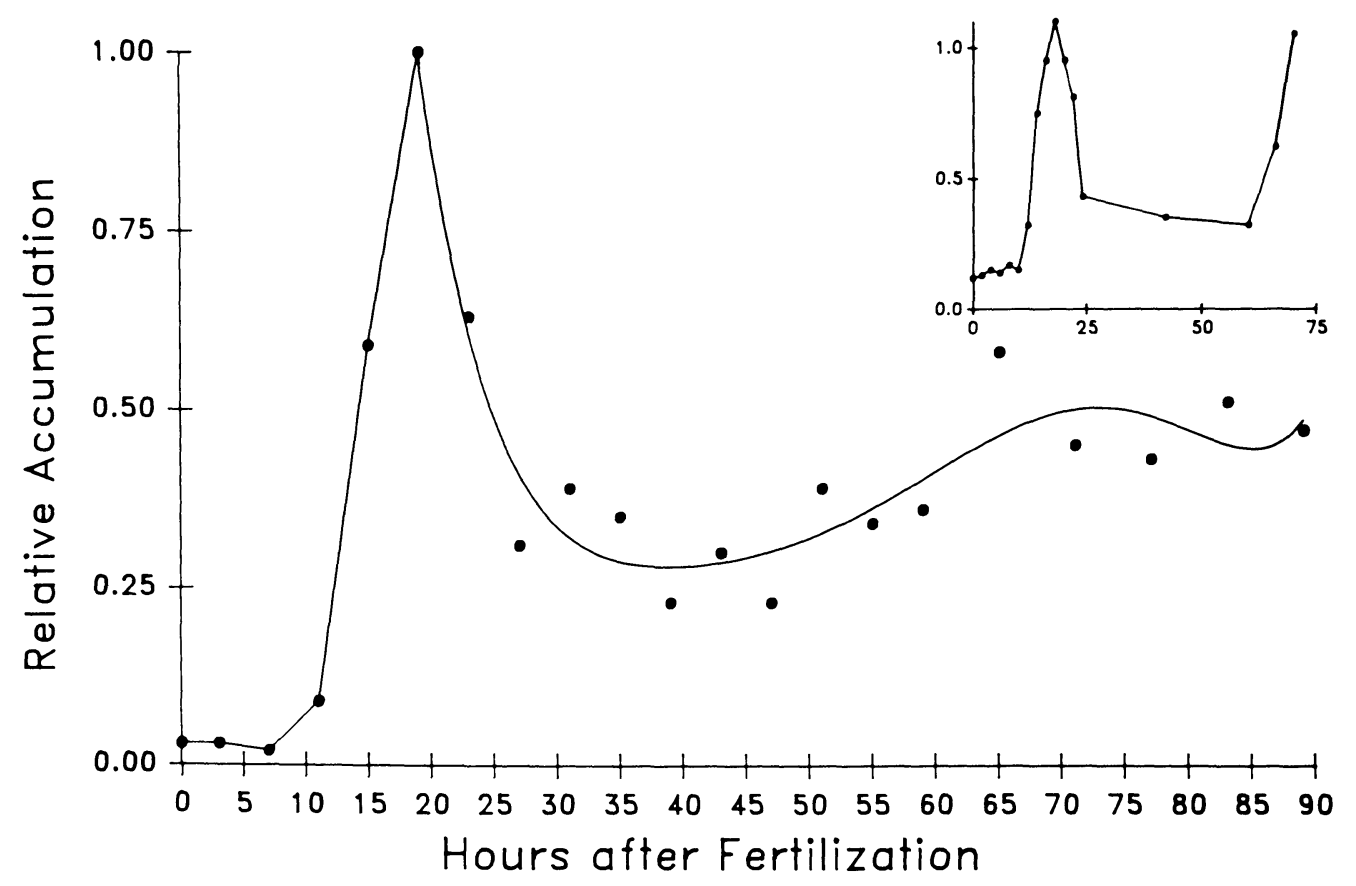

Figure 1. Relative accumulation of the Spec3 message at the times indicated during development. Inset shows $\beta_{1}$-tubulin message accumulation over the same period (replotted from Harlow and Nemer 1987a). Note that the ordinate of inset is molecules $\times 10^{5}$ per embryo. Under our culture conditions, blastulae hatch at approximately $19 \mathrm{hr}$ after fertilization, begin to gastrulate at $30 \mathrm{hr}$, assume a prism shape at $48 \mathrm{hr}$, and being to grow arms and become plutei at $72 \mathrm{hr}$. 
the sequence of the open reading frame is conserved between $S$. purpuratus and the distantly related species $L$. pictus, whereas the 3 ' untranslated region is not: a Spec 3 probe containing the open reading frame detected three bands in a blot of genomic DNA when hybridized at a moderately high stringency of $0.18 \mathrm{M} \mathrm{Na}^{+}$at $68^{\circ} \mathrm{C}$, whereas a probe containing only $3^{\prime}$ untranslated sequence did not (Eldon 1987).

\section{Spatial distribution of the Spec3 transcript during embryogenesis}

In situ hybridization shows that Spec3 mRNA is transiently synthesized in all regions of the very early blastula ( $12 \mathrm{hr})$, but rapidly becomes restricted to ectoderm lineages. In agreement with conclusions from the RNA blot analysis (Fig. 1), grain densities over sections of unfertilized eggs were not detectably higher than background (Fig. 2a). Two separate measurements indicated signals were three- and fourfold higher over sections of late cleavage-stage embyros $(12 \mathrm{hr}$, or about $160-180$ cells; Cox et al. 1984) than over sections of eggs. These new transcripts accumulate in all regions of the 12-hr embryo (Fig. 2b). In approximately $5 \%$ of randomly selected sections, we observed very small regions that appeared unlabeled, but corresponding areas in adjacent sections were labeled at the general level of the section. Thus, any regions free of Spec 3 mRNA are either small $1<5 \mu \mathrm{m}$ in diameter) or artifactually unlabeled. We conclude that all major lineages of the embryo (presumptive oral ectoderm, aboral ectoderm, primary mesenchyme, secondary mesenchyme, and endoderm) accumulate Spec3 mRNA during cleavage.

At early blastula stage before hatching (17 hr; Fig. 2c), the distribution of Spec3 mRNA is no longer uniform. In individual sections the majority of cells are heavily labeled, whereas one small region of contiguous cells is essentially unlabeled. The lack of distinguishing morphological characteristics prevents positive identification of the unlabeled cells at this stage, but they likely correspond to precursors of the thickened vegetal plate, which is the only consistently unlabeled region of the

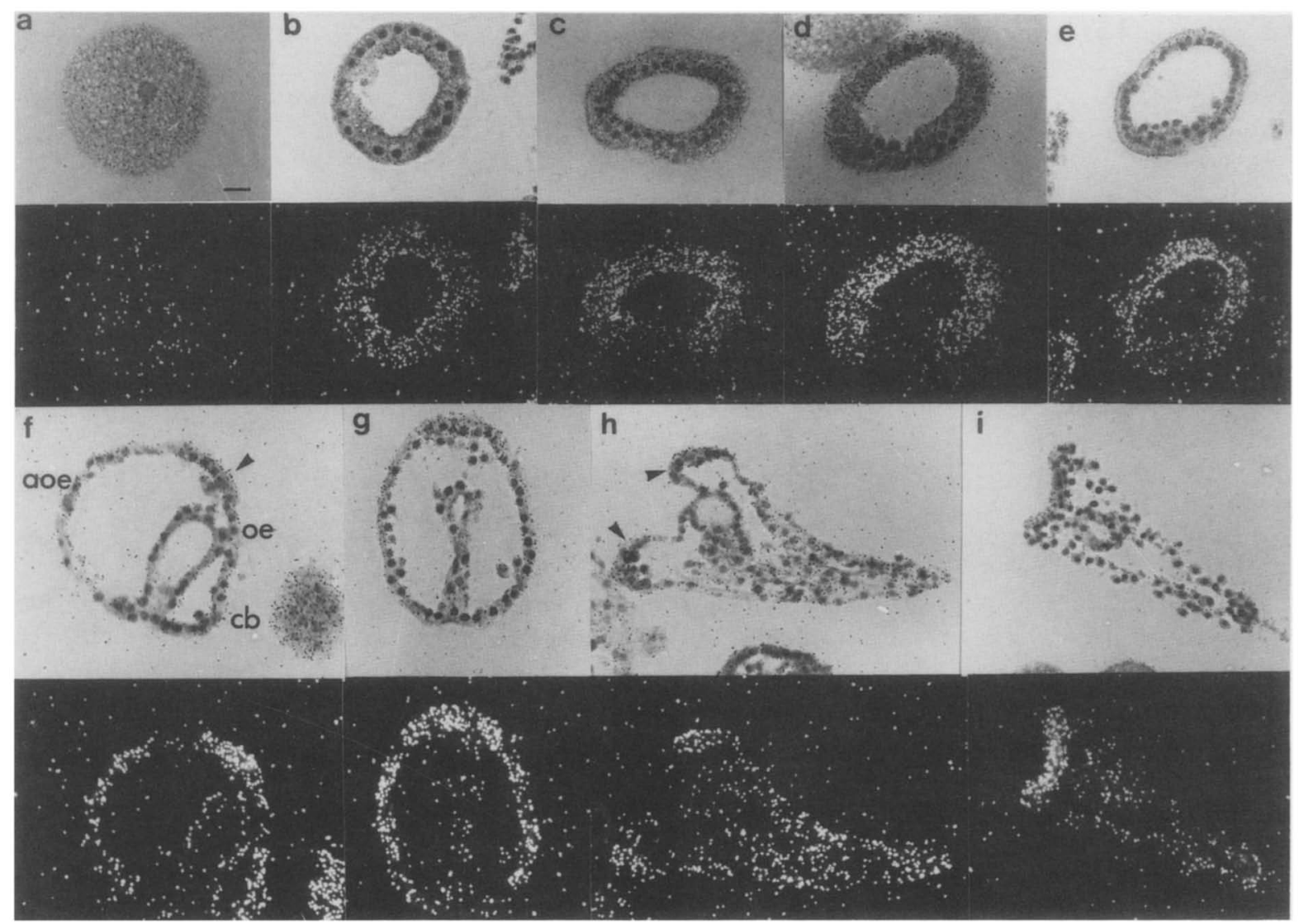

Figure 2. Distribution of Spec3 mRNA in sea urchin embryos. Sections of $S$. purpuratus embryos were prepared and hybridized with ${ }^{3} \mathrm{H}$-labeled antisense RNA probes as described in Methods. Shown are pairs of phase-contrast and dark-field photographs of egg $(a)$, 12-hr early blastula $(b), 17$-hr blastula $(c), 20$-hr hatched blastula $(d), 27-\mathrm{hr}$ mesenchyme blastula $(e)$, perpendicular sections through 55 -hr gastrula $(f, g), 73$-hr pluteus $(h)$, and 84 -hr pluteus $(i)$. All sections except that shown in $c$ were taken from the same slide; therefore, grain densities can be compared. The exposure time was 4 weeks. The section shown in $c$ was taken from another experiment in which the specific activity of the probe was lower $(82 \%)$ and the exposure time was 31 days. $(\nabla)$ Animal hemisphere; $(\nabla \nabla)$ margins of the ciliary band; (cb) presumptive ciliary hand; (aoe) presumptive aboral ectoderm; (oe) presumptive oral ectoderm. Bar in $a$ represents $10 \mu \mathrm{m}$. 
20-hr hatched blastula (Fig. 2d). In the mesenchyme blastula ( $27 \mathrm{hr}$; Fig. 2e), the unlabeled region includes all primary mesenchyme cells within the blastocoel as well as the vegetal plate, which includes presumptive endoderm, secondary mesenchyme, and derivatives of the small micromeres. Cells of these lineages remain unlabeled throughout the remainder of embryonic development. The labeled region includes the majority of the surface of the blastula, which gives rise to both oral and aboral ectoderm. In many sections of blastulae, grain densities are highest at the animal pole and gradually diminish from animal to vegetal pole (Fig. 2e). The animal pole includes cells that produce the apical tuft, a structure of long rigid cilia first observed after hatching.

At gastrula stage, labeling is restricted again to ectodermal lineages, and grain densities over ectoderm are clearly heterogeneous. Figure $2, \mathrm{f}$ and $\mathrm{g}$, shows two sections, both cut through the animal-vegetal axis but perpendicular to each other, which illustrate that signals are highest in the animal hemisphere and in the region of the presumptive ciliary band. Signals are intermediate in presumptive aboral ectoderm and undetectable in portions of presumptive oral ectoderm, endoderm, and mesenchyme. Analysis of serial sections leads us to believe that the section shown in Figure $2 \mathrm{~g}$ passes through the border of presumptive aboral and oral ectoderm. These are regions of contiguous cells, each comprising approximately one hemisphere of differentiating ectoderm (for example, see Lynn et al. 1983). The border between these regions contains cells of the presumptive ciliary band, and the unformly high labeling intensities observed here over ectoderm are consistent with this interpretation.

The relative distribution of Spec 3 mRNA established in various lineages at gastrula is maintained in the pluteus-stage larva. Grain densities observed in different sections vary somewhat, which appears to reflect actual differences in Spec3 mRNA content among different embryos, since quite similar levels of labeling are observed over corresponding regions of adjacent $5-\mu \mathrm{m} \mathrm{sec}-$ tions (data not shown). Signal intensity over the perimeter of oral ectoderm corresponding to ciliary band cells is always equal to, and often significantly higher than, that over aboral ectoderm. Labeling of ciliary band cells increases at late pluteus stage. For example, Figure $2 \mathrm{i}$ shows a section cut close and parallel to the anal side of the pluteus in which a strip of oral ectoderm lying between the postoral arms is heavily labeled. Little or no signal is observed over a different cell type comprising the face of the pluteus with the border of the ciliary band (Fig. 2h). Thus, at these late stages strong signals correlate again with the presence of ectodermal cilia.

We have analyzed the spatial pattern of accumulation of $\beta$-tubulin mRNAs in embryos of two urchin species using probes containing coding sequence. In both $L$. pictus (B2 probe; Alexandraki and Ruderman 1983) and, as illustrated in Figure 3 , in $S$. purpuratus ("blast jl" probe; Shepherd et al. 1983|, the distribution of $\beta$-tubulin mRNA is very similar to that of Spec3 throughout embryogenesis. In particular, grain densities are lowest at the vegetal pole of the blastula and in the gastrula archenteron, intermediate in aboral ectoderm and its precursors, and highest at the animal pole of blastula and gastrula, especially in the presumptive ciliated band (20 hr: cf. Figs. 2d and 3a; $44 \mathrm{hr}$ : cf. Figs. $2 \mathrm{f}$ and $3 \mathrm{~b}$ ). Figure $3 c$ shows that tubulin mRNAs are present throughout the pluteus at rather uniform concentration except for two- to threefold higher concentration in the ciliated band (see arrows in Fig. 3c). With respect to ectodermal lineages, the patterns are identical to those of Spec 3 mRNA ( $73 \mathrm{hr}$ : cf. Figs. $2 \mathrm{~h}$ and $3 \mathrm{c}$ ). The only noticeable difference in $S$. purpuruatus is that the tubulin probe gives some signal in endoderm and mesenchyme (see, e.g., Fig. 3c), because it cross-reacts with tubulin mRNAs that are not ectodermally restricted (Harlow and Nemer 1987a). The levels of signal obtained with Spec 3 and $\beta$-tubulin probes are in close agreement with their relative abundances as determined by RNA blotting and solution titration (Nemer 1986; Harlow and Nemer 1987a).

\section{Accumulation of Spec3 message in deciliated and cilia-regenerating embryos}

The congruence of temporal and spatial patterns of Spec 3 and $\beta$ - tubulin mRNAs suggested that Spec3 protein might be involved in ciliogenesis. To test this possibility, we measured the accumulation of Spec3 mRNA during regeneration of cilia after deciliation induced by hypertonic shock (Burns 1973). This approach has been used recently by Harlow and Nemer (1987b) and Gong and Brandhorst (1987) to monitor $\beta$-tubulin mRNA levels after deciliation in $S$. purpuratus and L. pictus, respectively. Deciliation causes a transient increase in the synthesis of tubulin and other proteins associated with cilia (Stephens 1977) which, in the case of tubulin, has been shown to be regulated mainly at the level of transcription (Gong and Brandhost 1987).

Replicate dot blots were prepared with total RNA isolated from gastrula regenerating cilia. We compared the response of Spec3 with that of tubulin using a $\beta$-tubulincoding sequence that hybridizes to all four known $\beta$-tubulin messages (Harlow and Nemer 1987a,b). As a control for nonspecific effects of deciliation, we used a probe for Spec1, an mRNA encoding a protein expressed in aboral ectoderm whose function is not expected to be related to ciliogenesis (Carpenter et al. 1984). The mitochondrial 16S rRNA probe was used to control for RNA loading and hybridization efficiency. Quantification of the results shows that both Spec3 (Fig. 4a) and $\beta$-tublin messages (Fig. 4b) increase coordinately three- to fourfold in the first 90 min after deciliation, then decrease. A second round of declilation produces a more rapid fourto fivefold accumulation of both messages with nearly identical kinetics. In contrast, Specl mRNA levels are unaffected by either round of deciliation. The decrease in Specl mRNA abundance over the 2-hr course of the experiment seen in both control and experimental cultures probably reflects the developmental decrease in message abundance seen for Specl at the late gastrula 


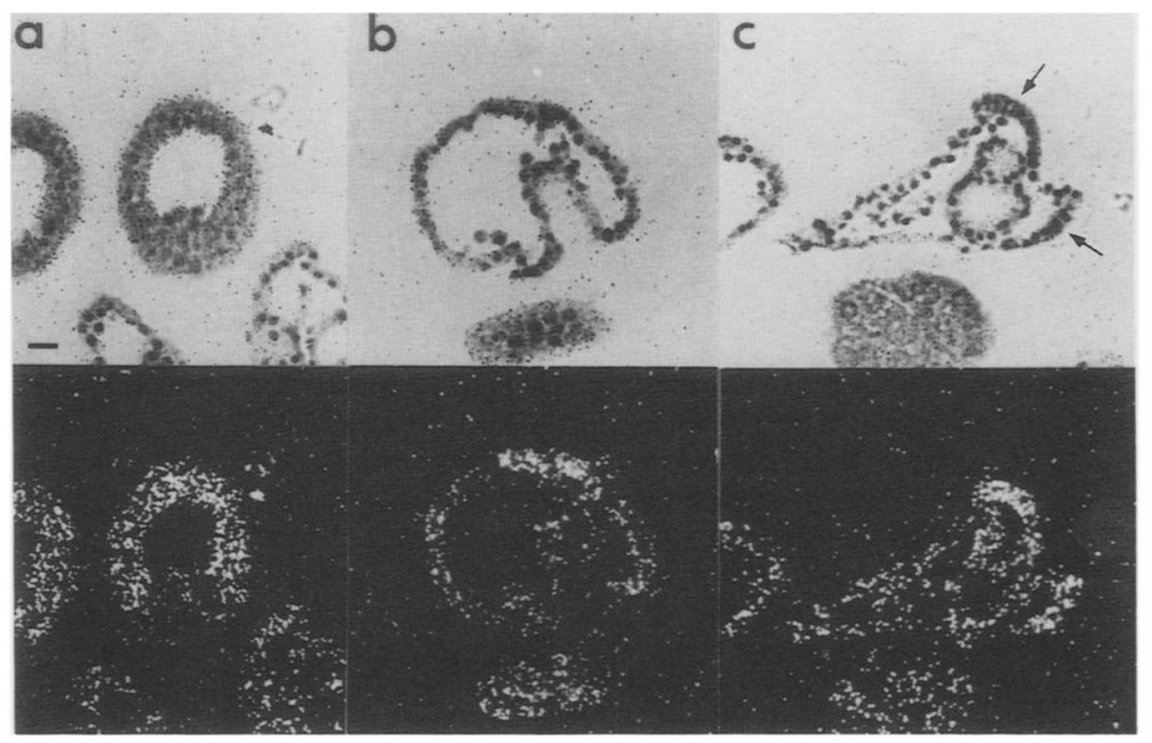

Figure 3. Distribution of $\beta$-tubulin mRNAs in sea urchin embryos. These in situ hybridizations were carried out in the same experiment as those shown in Fig. $2 a$, b, and $d-i$, using probes of the same specific activity. The sections in $a, b$, and $c$ are from the same stages and correspond to the same sectioning planes as those shown in Fig. $2 \mathrm{~d}(20 \mathrm{hr}), 2 \mathrm{f}(44 \mathrm{hr})$, and $2 \mathrm{~h}(73 \mathrm{hr})$, respectively. Signal intensities closely reflect relative concentrations of $\beta$-tubulin and Spec 3 mRNAs since the concentration of the former is three times higher, the complexity of the tubulin probe is $75 \%$ of that for Spec 3 , and the exposure was one-half as long (14 days). Taking these parameters into account, the signals shown above should be 1.1 times those shown in Spec3 mRNAs in Fig. 2. Arrows indicate margins of the ciliary band. Bar in $a$ represents $10 \mu \mathrm{m}$.

stage (Bruskin et al. 1981). We have performed identical experiments at blastula stage with similar results (data not shown; Eldon 1987), providing strong evidence that Spec3 is associated with ciliogenesis. Further strengthening this assertion are the results of Nemer (1986) and Harlow and Nemer (1987b), showing that animalization of embryos with $\mathrm{Zn}^{2+}$, which causes increased ciliation, results in increased levels of both Spec3 and $\beta$-tubulin mRNAs.

\section{The Spec3 open reading frame}

In our original report on Spec3 (Bruskin et al. 1981), we made use of a cDNA clone, pSpec3, which had a 1.15-kb insert and contained no signficant open reading frames. With it, we isolated a longer Spec3 cDNA clone with a $1.95-\mathrm{kb}$ insert only slightly smaller than the $2.0-\mathrm{kb}$ Spec3 transcript (Fig. 5). The two EcoRI fragments from the longer Spec3 clone were subcloned into either pUC or M13 vectors and designated Spec3-kappa and Spec3zeta (Fig. 5). Hybridizing single-stranded probes derived from Spec3-kappa to embyro RNA and sequencing Spec3-kappa defined the orientation of the Spec3 message and revealed an open reading frame beginning at the site of the EcoRI linker (added during the cloning procedure) and continuing 740 bases to the first translational stop codon, TAA.

To map the start of transcription, primer extension analysis was carried out. A synthetic primer complementary to the first 20 nucleotides of the putative protein coding sequence was hybridized to RNA isolated from blastula-stage embryos and extended using reverse transcriptase. As shown in Figure 6, the product of this reaction is a single fragment 152 bases long, 24 bases longer than the cDNA. Chain-termination sequencing of the genomic phage encoding the transcript was primed with the synthetic oligomer and run on the same denaturing acrylamide gel. The alignment of the extension product with the sequencing lanes reveals the nucleotide initiating transcription to be $\mathrm{G}$, as indicated in Figure $7 \mathrm{a}$. The first methionine in the only open reading frame occurs at position 133 and is assumed to be the start of translation of the Spec3 protein. The protein translated from this reading frame would be 208 amino acids long.

Several features of the predicted amino acid composition (Table 1) and sequence (Fig. 7a) are unusual. Acidic and basic amino acids are very rare; there are only five aspartic acids, three lysines, three histidines, and one arginine; glutamic acid is absent. Most of the nonpolar amino acids are arranged in a highly ordered pattern in the carboxy-terminal half of the protein (see Fig. 7b). The proline content is extremely high $(14 \%)$ and is distributed asymmetrically in the protein sequence; all 29 prolines occur within the amino-terminal 138 residues, and 23 prolines occur within the first 63 residues. The sequence is highly reiterative: in 19 places a single amino acid is repeated twice, in eight places a single amino acid is repeated three times, and in three places a single amino acid is repeated four times. In addition, a sixamino-acid sequence is repeated three times, and an overlapping region of 15 amino acids is repeated twice. The placement of these reiterations is detailed in the legend to Figure 7a. There is also a single site for aminolinked glycosylation (Asn-Asn-Thr) and a single Lys-Lys 

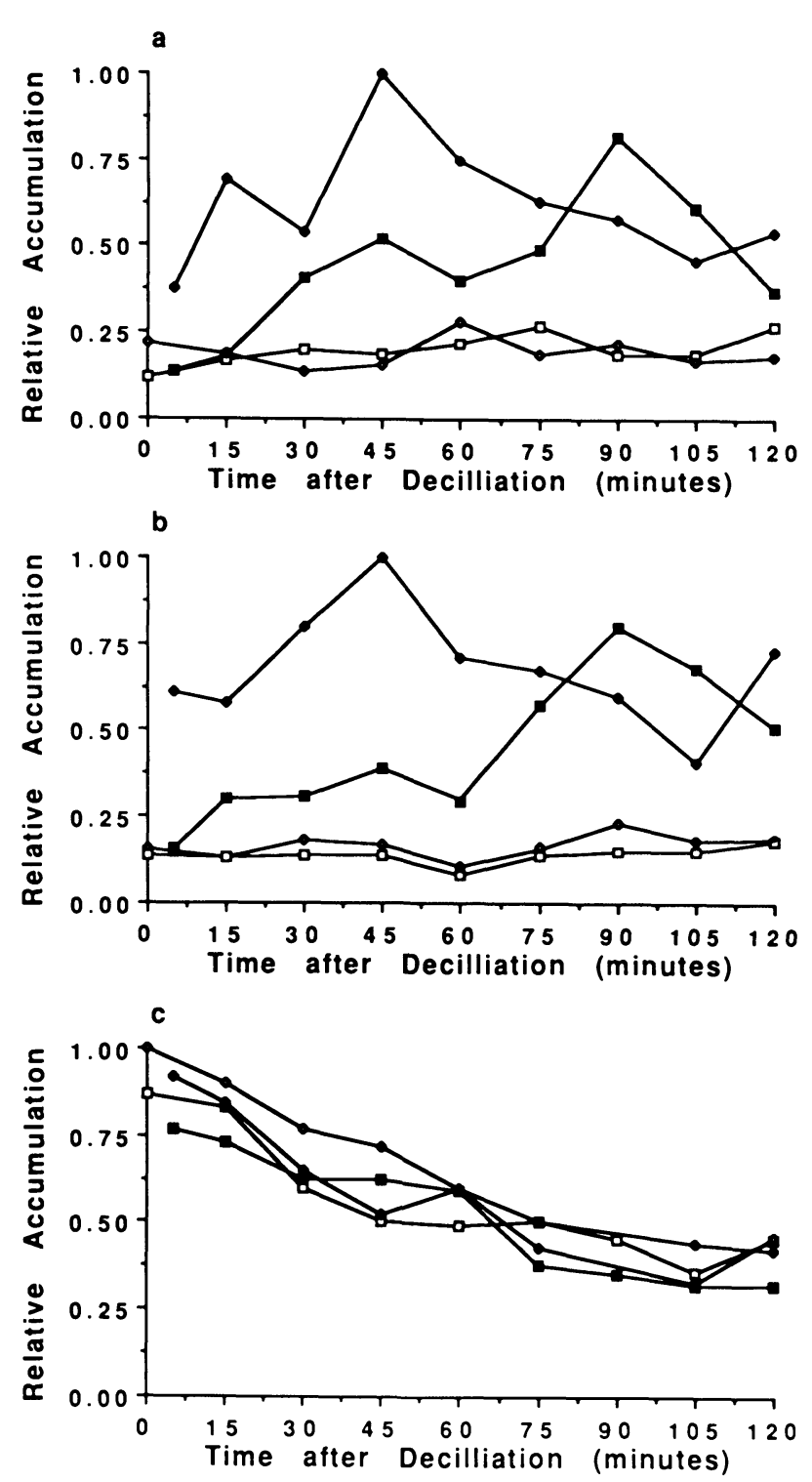

Figure 4. Quantity of Spec3, $\beta$-tubulin, and Specl RNA synthesized following deciliation of gastrula-stage embryos. $|a|$ Spec3; (b) $\beta$-tubulin; (c) Specl. ( $\square$ ) First deciliation; $(\bullet)$ second deciliation; $(\square)$ first control; $(\diamond)$ second control.

pair, which could act as a peptide cleavage site (Fig. 7a).

A Kyte-Doolittle hydropathy plot (Kyte and Doolittle 1982) of the putative Spec3 protein displays several distinctive features (Fig. 7b). Despite high overall hydrophobicity there is no amino-terminal signal peptide. Rather, near the amino-terminus is a long hydrophilic region (residues 10-70). In contrast, the carboxy-terminal half of the molecule contains two strongly hydrophobic regions, spanning residues $105-136$ and residues 146-183, bounded by short stretches of hydrophilic residues. Nine of the 12 charged amino acids found in the protein sequence occur in these hydrophilic stretches (small arrowheads, Fig. $7 \mathrm{~b}$ ). The nonrandom distribution of acidic and basic residues and the sharp boundaries between hydrophilic and hydrophobic domains argue that these regions have structural significance.

\section{A single Spec3 gene}

To determine the number of genes contributing to the complex temporal and spatial patterns of Spec3 expression, we used the 1.34-kb EcoRI-BamHI fragment of the Spec3-kappa subclone (Fig. 5) to isolate the number of recombinant $\lambda$ phages from a $\lambda E M B L 3$ genomic DNA library made from a Sau3A partial digestion of $S$. purpuratus sperm DNA. All of the recombinant inserts derived from a single overlapping region of the genome as judged by their restriction maps. Southern hybridization analysis of one genomic recombinant, phage 39, using the Spec3-kappa and -zeta cDNA clones as probes, defined restriction fragments containing Spec3 sequences. These restriction fragments were partially sequenced to determine their similarities with the Spec3 cDNA clones and to identify the exon-intron boundaries. The results of this analysis (summarized in Fig. 8) indicate that phage 39 contains an entire Spec3 gene and that, where sequences could be compared, the match with the cloned cDNA is greater than $95 \%$ (data not shown; Eldon 1988). The Spec3 gene is $4 \mathrm{~kb}$ long and is composed of 3 exons, $0.51 \mathrm{~kb}, 0.18 \mathrm{~kb}$, and approximately 1.4 $\mathrm{kb}$ long. The introns are clearly bounded by consensus splice sequences and are $1.4 \mathrm{~kb}$ and $0.32 \mathrm{~kb}$ in length (Fig. 8). The message size as measured by RNA gel blots corresponds closely to the sum of the exon sizes.

Though the genomic library screen yielded only one region of the $S$. purpuratus genome and sequencing showed a high degree of match with the cDNA clones, it was still possible that other Spec3 genes existed that were not represented in the $\lambda E M B L 3$ library. That this is not the case is shown by gel blots of sperm DNA from
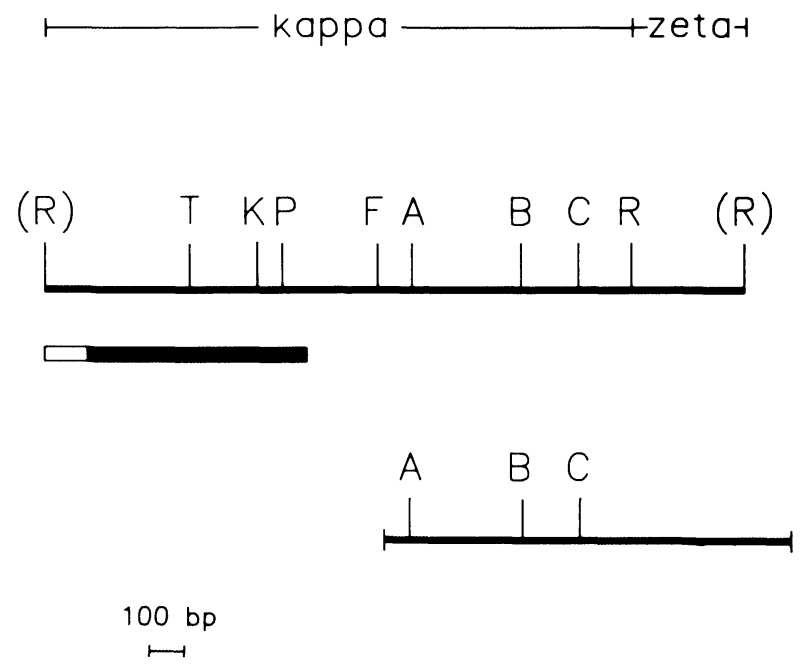

Figure 5. Restriction maps of Spec3 cDNA clones. The upper map is the nearly full-length clone isolated from a $\lambda$ gt 10 library. The bars indicate the two EcoRI fragments, kappa and zeta, that were subcloned. The open reading frame is indicated by the box, the dark portion of which indicates the putative protein coding region. The lower map is the original Spec3 isolate (Bruskin et al. 1981). Restriction sites: (A) XbaI; (B) BamHI; (C) HincII; (F) HinfI; (K) KpnI; (P) PvuII; (R) EcoRI; (T) PstI. 


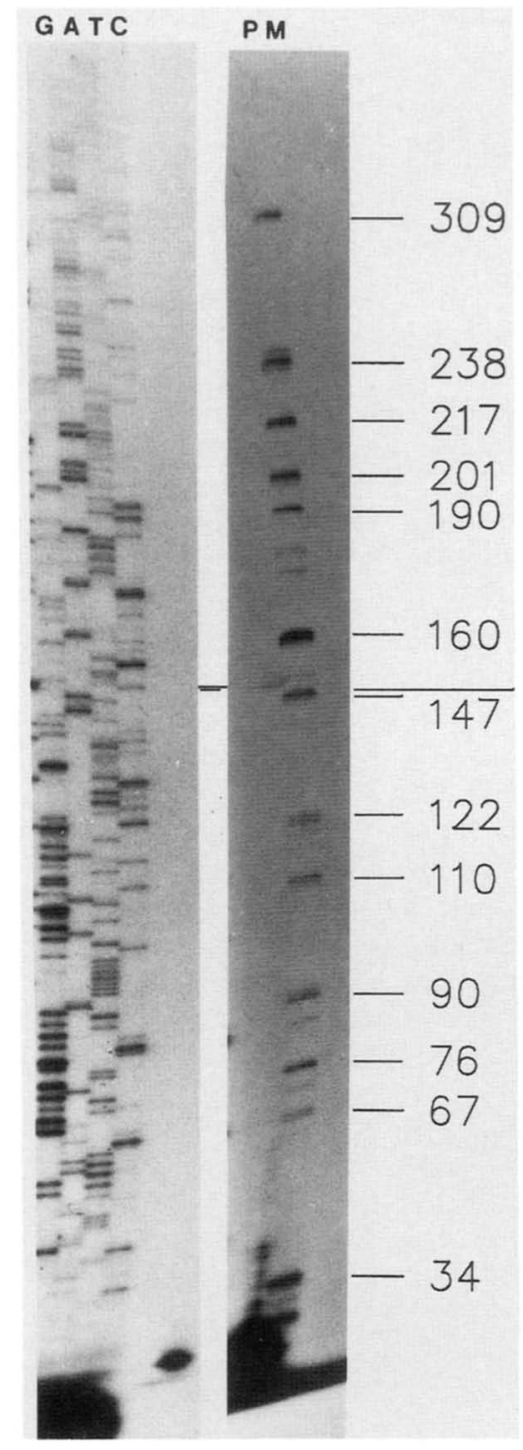

Figure 6. Determination of the site of transcription initiation. (Left) A genomic clone containing the region of transcription and translation initiation was sequenced using the synthetic 20-base primer complementary to the first 20 nucleotides of the translation product. Reaction lanes are indicated. (Right) Products of extension reaction using the same synthetic 20base primer and $50 \mu \mathrm{g}$ blastula RNA (lane P) and end-labeled products of $M s p I$ digestion of pBR322 (lane M). Fragment sizes are indicated. The bar connects the extension product and the band on the sequencing ladder to which it corresponds. Panels are taken from two exposures of the same gel.

several individuals. In the experiment shown in Figure 9, DNA from four individuals was digested with EcoRI and $X b a \mathrm{I}$ and the blots were probed with the $1.0-\mathrm{kb}$ EcoRI-XbaI fragment of the Spec3-kappa clone (cf. Fig. 5). Also included in this experiment was an EcoRI, XbaI digestion of phage 39 (Fig. 9, lane 5). As predicted from the restriction map, the probe hybridized to two phage 39 fragments, a 3.4-kb fragment containing exon 1 and a 1.6-kb fragment containing exon 2 and part of exon 3. Individual 3 (Fig. 9, lane 2) shows the identical hybrid-
Table 1. Amino acid composition of the Spec3 translation product

\begin{tabular}{|c|c|c|c|}
\hline & Amino acid & Number & Percent \\
\hline \multirow[t]{9}{*}{ Nonpolar } & Ala & 22 & 10.6 \\
\hline & Val & 11 & 5.3 \\
\hline & Leu & 8 & 3.8 \\
\hline & Ile & 18 & 8.7 \\
\hline & Pro & 29 & 13.9 \\
\hline & Met & 7 & 3.7 \\
\hline & Phe & 10 & 4.8 \\
\hline & Trp & 5 & 2.4 \\
\hline & & & $\overline{53.2}$ \\
\hline \multirow[t]{8}{*}{ Polar } & Gly & 28 & 13.5 \\
\hline & Ser & 4 & 1.9 \\
\hline & Thr & 12 & 5.8 \\
\hline & Cys & 6 & 3.4 \\
\hline & Tyr & 7 & 3.4 \\
\hline & Asn & 14 & 6.7 \\
\hline & Gln & 15 & 7.2 \\
\hline & & & $\overline{41.9}$ \\
\hline \multirow[t]{3}{*}{ Acidic } & Asp & 5 & 2.4 \\
\hline & Glu & 0 & 0.0 \\
\hline & & & $\overline{2.4}$ \\
\hline \multirow[t]{4}{*}{ Basic } & Lys & 3 & 1.4 \\
\hline & Arg & 1 & 0.5 \\
\hline & $\mathrm{His}$ & 3 & 1.4 \\
\hline & & & 3.3 \\
\hline
\end{tabular}

ization pattern as phage 39 , indicating that under these hybridization conditions phage 39 represents the only Spec3 gene in this apparently homozygous animal. Individual 2 (Fig. 9, lane 1) shows a composite pattern: Two bands match the phage 39 pattern, and two bands at 4.1 $\mathrm{kb}$ and $1.8 \mathrm{~kb}$ appear in the same intensity ratio as the 3.4- and 1.6-kb bands. Presumably, this individual is heterozygous for the Spec3 EcoRI-XbaI fragments due to restriction fragment length polymorphisms at the Spec3 locus. DNA of individual 11 (Fig. 9, lane 4) was used to construct the EMBL3 genomic library; this individual is also heterozygous, with phage 39 representing one of the alleles. DNA from individual 7 (Fig. 9, lane 3) shows four bands, one that is novel and three that correspond to bands seen in individuals 2, 3, and 11. No additional bands appear when the stringency of the final wash is reduced to $0.15 \mathrm{M} \mathrm{Na}^{+}, 55^{\circ} \mathrm{C}$ (data not shown). It is clear from the genomic DNA blot analysis that the Spec3 gene is single copy and polymorphic with respect to the length of the EcoRI-XbaI fragment. Direct comparisons between different cDNA clones and genomic clones show minor variation in sequence, demonstrating that single base pair polymorphisms also occur throughout the length of the gene (data not shown; Eldon 1988).

\section{Discussion}

\section{Correlation of the Spec3 message with ciliogenesis}

Our results provide strong circumstantial evidence that the Spec3 message encodes a protein associated with ectodermal ciliogenesis, though it may have other tu- 
bulin-associated functions as well. The temporal pattern of accumulation of Spec3 mRNA is quite similar to that of the ectoderm-enriched $\beta$-tubulin mRNAs previously identified (Nemer 1986; Harlow and Nemer 1987a). The rapid accumulation of these transcripts begins at late cleavage stage and coincides roughly with the initial elaboration of cilia; the second peak of accumulation coincides with the appearance of the ciliary band on the

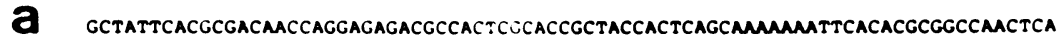
CACTCGTGGATATACACATTTAAATTTTGGATTTUTTGGAatTTACTGMTAM ATG GCT CAA GTT GCA CTT
MET ALA GLN VAL ALA PRO

ACA GGA GCC CCA ACC GAT GCT CCC CCT GCT TAT CCA CCT CCC CCT CAG CAG GCA CCA CCC ACA GG GC PCA ACR GAT GCT CCC CCT GCT TAT CCA CCT CCC CCT CAG CAG GCA CRA PRO
THR GLY ALA PRO THR ASP ALA PRO PRO ALA TYR PRO PRO PRO PRO GLN GLN ALA PRO PRO
10 10

CCA CAA CAG CCA GGA TAT GGC CAA CCA CAA CTA GGG TAT GGC CAA CCA CCA CCA CAA CTA PRO GLN GLN PRO GLY TYR GLY GLN PRO GLN LEU GLY TYR GLY GLN PRO PRO PRO GLN LEU

GGG TAT GGC CAA CCA CCA CCA CAA CGA GGG TAT GGA TAC CCT CCT CCT CCT CAA AAC AAC GLY TYR GLY GLN PRO PRO PRO GLN LEU GLY TYR GLY TYR PRO PRO PRO PRO GLN ASN ASN

AAC ATG ATG ATG AAC AAC ACC GTG GTC GTC ACC GCA CCC GCC CCC GCT CCC GCA AAC AAC ASN MET MET MET ASN ASN THR VAL VAL VAL THR ALA PRO ALA PRO ALA PRO ALA ASN ASN GTC CTC ATC ATC AAC CAG AAG AAG GAC AAC TGC TGC AGA CAA GCC ATC CCA GCC CAC CAC VAL VAL ILE ILE ASN GLN LYS LYS ASP ASN CYS CYS ARG GLN ALA ILE PRO ALA HIS HIS 90 100

ATC GCC GCC GCT ATC CTA TGT CTT ATT TTC AAC ATC TTC TTC CCC GGC ATT GGT ACG ATC ile ala ala ala ile LeU CyS LEU ILE PHE ASN ILE PHE PHE PRO GLY ILE GLY THR ILE 110 120

ATT GCT GGT TTC GCT GTG TTC TGT TGC GGT AAC CCC GGA GCG GAT GGA GGA AGC AAG GTC ILE ALA GLY PHE ALA VAL PHE CYS CYS GLY ASN PRO GLY ALA ASP GLY GLY SER LYS VAL 130 140

GGG ACA ATC TGC ATC AAC TTC TGG ATC GGC CTC CTC CAA ATC GTT ACC GTT TGG TTC TTT GLY THR MET CYS ILE ASN PHE TRP ILE GLY LEU LEU GLN ILE GLY THR VAL TRP PHE PHE
150 TTC CTT GGC TGG ATC TGG TCC ATC ATG TGG GGC GCT GCT TTC ATC GGC ATG TCA GCT GAT $\begin{aligned} \text { PHE LEU GLY TRP ILE TRP SER ILE MET TRP GLY ALA ALA PHE ILE GLY MET SER ALA ASP } & \\ & 170\end{aligned}$

TAT CAT TCC GGT GGA GAT ACC ACT ATT GTA GCC ACT GGT GGC GGA GGA ACC ACA GTC ATC TYR HIS SER GLY GLY ASP THR THR ILE VAL ALA THR GLY GLY GLY GLY THR THR VAL ILE
190

AAC AAC TAA ACTCGACTTCAAGACAAAATGATAA...1159 nucleotides... CAATtaTCCTATGTTAAAAT ASN ASN --.

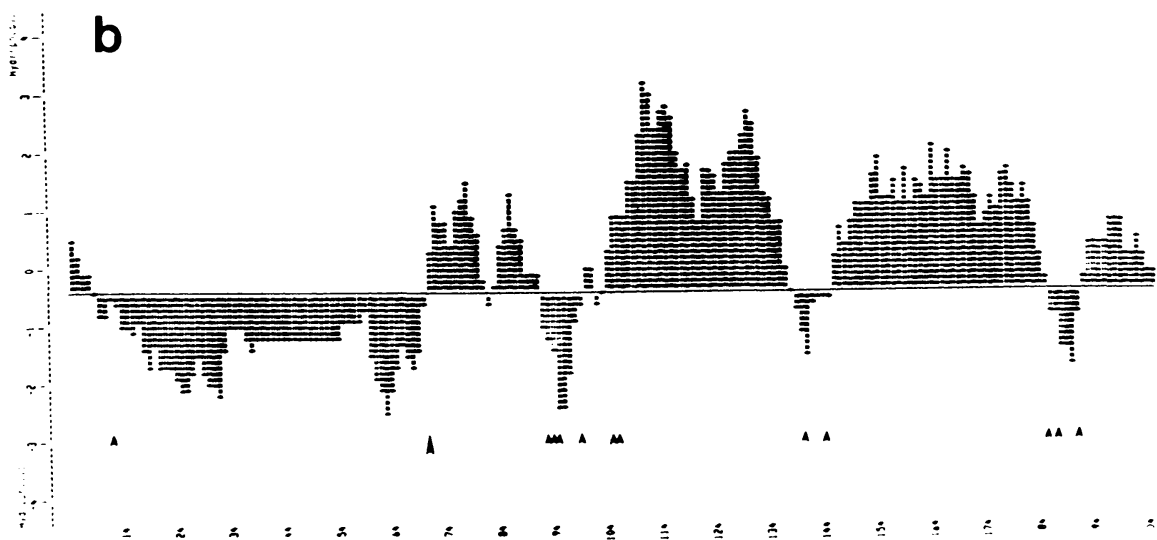

Figure 7. Putative Spec3 protein sequence and hydropathy plot. $(a)$ Nucleic acid and amino acid sequence of Spec3. The nucleic acid sequence begins at the base identified by primer extension analysis as the start of transcription and ends at the end of the zeta subclone. The only significant open reading frame is translated beginning at the first in-frame methionine residue. The six-amino-acid sequence Pro-Gln-Leu-Gly-Tyr-Gly is repeated three times (residues 35-40, 44-49, and 53-58). The 15-amino-acid sequence ProGln-Leu-Gly-Tyr-Gly-Gln-Pro-Pro-Pro-Gln-Leu-Gly-Tyr-Gly is repeated twice (residues 35-49 and 45-58). In addition, single amino acids are duplicated. Proline (residues 18-21 and 60-63) and glycine (residues 199-202) are repeated four times. Six amino acids are reiterated three times: proline (25-27, 42-44, and 51-53), asparagine (65-67), methionine (68-70), valine (74-76), alanine (108-110), and phenylalanine (165-167). Thirteen amino acids are repeated twice: asparagine (71-72, 85-86, and 207-208), cysteine (97-98 and 134-135), glutamic acid (22-23 and 28-29), glycine (142-143 and 190-191), isoleucine (89-90 and 126-127), alanine (178-179), histidine (105-106), leucine (157-158), lysine (93-94), phenylalanine (119-120), proline (14-15), threonine (193-194), and valine (87-88). (b) Kyte-Doolittle hydropathy analysis (Pustell Sequence Analysis Program, IBI) using nine-amino-acid segments. Small arrowheads indicate the sites of the 12 charged amino acid residues, and the large arrowhead indicates the site of potential amino-linked glycosylation. 


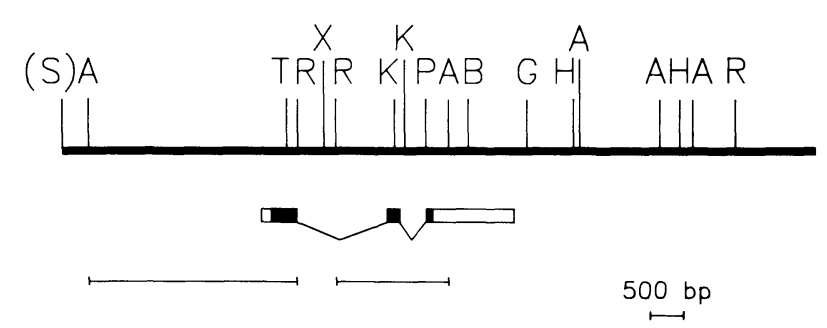

Figure 8. Spec3 gene structure. A partial restriction map of 11 $\mathrm{kb}$ at the $5^{\prime}$ end of the phage 39 insert is shown. A portion of this region encodes the Spec 3 transcript. The boxes indicate the three exons of the mature mRNA transcript connected by lines indicating the two introns. Shaded areas indicate the presumed protein coding region. The bars below the map indicate the two $E c o \mathrm{RI}-X b a \mathrm{I}$ fragments of genomic DNA detected by the probe used for genomic DNA blots (Fig. 9|. Restriction sites are: (A) XbaI; (B) BamHI; (G) BglII; (H) HindIII; (K) KpnI; (P) PvuII; (R) EcoRI; (T) PstI; (X) XhoI.

prism-stage embryo. In situ hybridization shows highest accumulation of Spec 3 and $\beta$-tubulin mRNAs in regions thought to be actively involved in producing cilia. The gradation in grain intensities seen with the Spec 3 and $\beta$ tubulin probes at blastula stages reflects the apparent length gradient of cilia on the embryo. Cilia, including the apical tuft cilia, have been found to be longest at the animal pole and shortest at the vegetal pole (RiedererHenderson and Rosenbaum 1979; Harlow and Nemer 1987b). High grain densities are clearly associated with the ciliary band, a distinct cluster of ciliated columnar or pear-shaped cells that extends around the circumference of the oral surface of prism- and pluteus-stage embyros. Deciliation and subsequent cilia regeneration results in a transient four- to fivefold increase in the levels of the Spec3 and $\beta$-tubulin mRNAs, but not of Specl mRNA, whose expression is probably unrelated to ciliogenesis. In addition, embryos that have been animalized and induced to grow excessive cilia by treatment with $\mathrm{Zn}^{2+}$ synthesize increased levels of both Spec3 and $\beta$-tubulin mRNAs (Nemer 1986; Harlow and Nemer 1987b). Stephens (1977) has shown that the synthesis of several ciliary proteins is increased during cilia regeneration, and several studies demonstrate that $\beta$-tublin mRNA levels are increased during cilia regeneration (Merlino et al. 1978; Gong and Brandhorst 1987; Harlow and Nemer 1987b). In Chlamydomonas, regeneration of flagella results in a similar reduction of $\alpha$ - and $\beta$-tubulin mRNAs and mRNAs encoding other cilia-associated proteins (Lefebvre et al. 1980; Baker et al. 1984; Schloss et al. 1984; Williams et al. 1986). In the case of $\alpha$ - and $\beta$-tubulin, this induction involves new transcription as well as increased stability of the mRNA (Baker et al. 1984).

In $S$. purpuratus, cilia appear during the early blastula stages on the apical surface of all blastomeres, with the possible exception of mesenchyme cell precursors. Our in situ hybridization data show no grains above background in differentiated endoderm cells, yet at least some of these cells do have cilia. The cells of the midand hindgut are ciliated on the luminal side, consistent with the presence of cilia on their apical surface before invagination, though it is not clear whether or not those of the foregut are ciliated (G. Wessel, pers. comm.). In $L$. variegatus, cilia on invaginating endodermal cells are shorter and stubbier than ectodermal cilia, suggesting structural differences (Morrill and Santos 1985). Because we detect no Spec3 message in endoderm tissue, we assume that the Spec3 protein is not associated with endodermal cilia.

The quantity of the Spec3 transcript can be roughly estimated by comparison with $\beta$-tubulin message, which has been quantified by Harlow and Nemer (1987a). They found that there are $3.5 \times 10^{5} \beta$-tubulin mRNA molecules per embryo at hatching blastula stage, and that about one-third of these are the ectoderm-specific $\beta_{1}$-tubulin mRNA. The abundance of Spec3 transcripts is also one-third that of total $\beta$-tubulin mRNA at this stage (Nemer 1986). This correspondence suggests a developmental coupling of the Spec 3 and $\beta_{1}$-tubulin mRNAs that is quantitative as well as qualitative. If the translation rate and stability of the Spec3 protein were similar to that of $\beta_{1}$-tubulin, the new embryonic Spec3 protein would be quite abundant and possibly stoichiometric with $\beta_{1}$-tubulin. Whether or not there are maternal stockpiles of Spec3 protein similar to the large quantities of tubulin subunits stored in the egg is unknown, so the relative abundance of tubulin and Spec3 protein in the embryo cannot yet be determined.

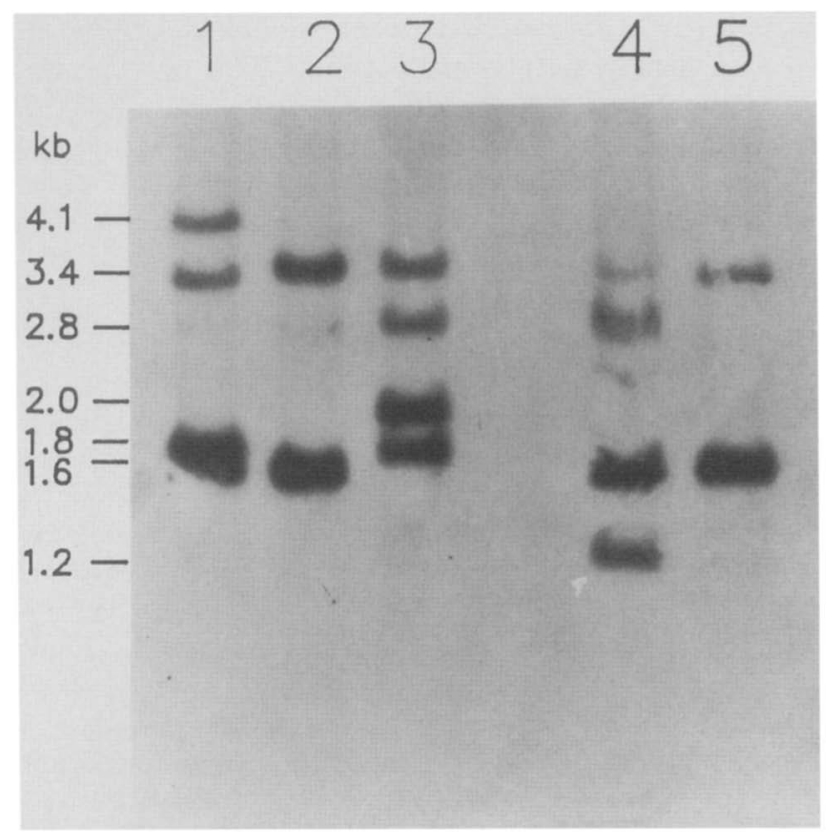

Figure 9. Representation of the Spec3 gene in the genome. A Southern blot of $E c o R I-X b a I$ digests of DNA from the genomes of four individuals was hybridized with the EcoRI-XbaI fragment of the Spec3-kappa cDNA subcloned into M13mpl9. (Lanes 1-4) Individuals 2, 3, 7, and 11, respectively; (lane 5) phage 39 digested with EcoRI-XbaI (Fig. 8). Fragment sizes are indicated. The stronger hybridization intensity of the $1.2-$ to $2.0-\mathrm{kb}$ bands are due to asymmetric labeling of the probe because the phage 39 bands (lane 5) show the same asymmetric hybridization pattern. 
The fact that the Spec 3 message accumulates to onethird the level of total $\beta$-tubulin message during development suggests that the Spec3 product is not a minor cellular protein. It may be that the Spec3 protein is not specific to cilia but is also associated with other microtubule structures such as the mitotic spindle or the cytoskeleton, much as the testes-specific $\beta_{2}$-tubulin in Drosophila is found in the meiotic spindles and cytoplasmic microtubules as well as in the sperm axoneme (Kemphues et al. 1982).

\section{Temporal and spatial expression of Spec3 mRNA}

The Spec3 mRNA is one of the earliest known developmentally regulated transcripts, accumulating in embryos as early as $12 \mathrm{hr}$ after fertilization. The initial accumulation clearly takes place in all blastomeres, and the pattern of differential expression is established by sequential disappearance of Spec3 mRNA from different lineages. The transient decrease in Spec3 mRNA content between blastula and gastrula stages reflects both its loss from some lineages and its decreased levels in others. The mRNA disappears from endoderm and mesenchyme cells after 12 and probably closer to $17 \mathrm{hr}$, at about the time when cell cycle synchrony breaks down and cell division slows. The rapid disappearance of Spec3 mRNA implies a short half-life in these cells. Thus, the expression and decay of the Spec3 message is one of the earliest events of gene regulation identified for mesenchyme and endoderm cells. Spec 3 mRNA is present in the entire ectoderm at high concentrations in the early blastula stages and persists at diminishing concentrations until pluteus. This implies either that there is continuing synthesis of Spec3 mRNA at low levels or that the mRNA synthesized earlier is rather stable later in development.

\section{The Spec3 protein}

We used the Bionet Computer Resource to search for protein sequences with similarities to the Spec3 open reading frame and found no significant matches. This is not surprising even if the Spec3 protein is a component of the cilium per se. This structure contains a complex assortment of more than 150 proteins (Piperno et al. 1977), and although several of the accessory proteins of cilia and flagella axonemes have been identified, including dynein arm components (Mitchell and Rosenbaum 1985) and radial spoke proteins (Piperno et al. 1981), there is little sequence information available for any of them. Recently cDNA clones specifying different radial spoke proteins and dynein from Chlamydomonas have been isolated (Williams et al. 1986), and the messages are all induced to varying extents upon deflagellation and regeneration. Whether the Spec3 protein has sequence similarities with any of these proteins remains to be seen.

We have been unable to identify the Spec3 proteins in vivo using several approaches (Eldon 1988). Brandhorst and his colleagues have performed an extensive analysis of the temporal and spatial patterns of protein synthesis in $S$. purpuratus using two-dimensional polyacrylamide gels (Bruskin et al. 1982; Bedard and Brandhorst 1983), and close inspection of these gels shows no protein with the early temporal appearance and ectodermal specificity expected for the Spec3 protein. Given the long hydrophobic stretches and high proline content present in the Spec3 protein, it is possible that it has unusual physical properties. It is also possible that the Spec3 protein is modified post-translationally by proteolytic processing, glycosylation, or other modifications, and is not resolvable on two-dimensional gels.

The sequence and hydrophobicity analysis of the Spec3 open reading frame indicates that the putative protein has two distinct regions. The amino-terminal portion (residues 1-91) is hydrophilic, contains 26 of the 29 prolines, and has a site for amino-linked glycosylation. The carboxy-terminal portion (residues 92-208) is highly hydrophobic and contains two long hydrophobic stretches bounded by short hydrophilic linkers, where nine of the 12 charged amino acids reside. The presence of the hydrophobic regions suggests to us that the Spec3 protein may be associated with the plasma membrane of cilia via two potential $\alpha$-helical membrane-spanning regions. The Spec3 translation product appears to lack an amino-terminal signal sequence, but several membrane proteins have been identified that use regions other than their amino terminus for membrane insertion (Wickner and Lodish 1985). It is possible that the extensive hydrophobic regions found in the Spec 3 translation product allow its incorporation into some other hydrophobic environments within the cell, such as nonmembranous lipids or other proteins of a hydrophobic nature.

\section{The Spec3 gene}

The complex temporal and spatial expression of the Spec3 mRNA was monitored with probes containing Spec 3 coding sequences. It is conceivable that this complexity could be the result of cross-hybridization of multiple Spec3 genes, each with its own pattern of expression. For example, the observation that the Spec3 transcripts are present in all cells at $12 \mathrm{hr}$ after fertilization but restricted to ectodermal cells by $17 \mathrm{hr}$ after fertilization could be explained by the existence of two Spec3 genes: one expressed initially in all cells and ceasing expression by $17 \mathrm{hr}$ postfertilization, and the other expressed only in ectodermal cells beginning at about $17 \mathrm{hr}$ after fertilization. Differential expression of individual members of multiple gene families has been reported in sea urchin embryos for genes encoding actins (Cox et al. 1986; Lee et al. 1986), histones (Mohun et al. 1985), $\beta$ tubulins (Alexandraki and Ruderman 1985; Harlow and Nemer 1987), and metallothioneins (Wilkinson and Nemer 1987). However, our data demonstrate that multiple Spec3 genes do not exist and that expression from a single Spec3 gene is responsible for the patterns we observe. We isolated only a single region of the $S$. purpuratus genome that contained Spec3 sequences, and hybridization of Spec3 coding sequences with genomic DNA, even under low stringencies, yielded patterns indicating a single polymorphic gene.

Rather than representing a gene whose expression is 
associated with the differentiation of a distinct cell lineage of cell type, as is the case for several genes recently described in sea urchins (Davidson 1986), expression of the Spec3 appears, at least in part, to be associated with a developmental and physiological process - that of ectodermal ciliogenesis. The strong coupling of the Spec3 gene with the $\beta$-tubulin genes suggests that identical regulatory mechanisms control their expression. In particular, the stability of $\beta$-tubulin mRNA in most systems is controlled by the pool of $\beta$-tubulin monomer (Cleveland et al. 1981). It will be of interest to ask whether the Spec3 message stability is under similar control.

\section{Methods \\ Embryo culture}

Embryos were cultured at a density of $10^{3}-10^{4} / \mathrm{ml}$ in artificial seawater (McClay 1986) at $14-15^{\circ} \mathrm{C}$ with constant stirring.

\section{Hybridization probes from single-stranded M13 templates}

Single-stranded M13 templates were hybridized to a 16-base hybridization probe primer (New England Biolabs) and elongated using the Klenow fragment of $E$. coli polymerase I (BRL) in the presence of a mix of dATP, dCTP, TTP (Pharmacia), and $[\alpha-32 \mathrm{P}] \mathrm{dCTP}$ (Amersham) at $30^{\circ} \mathrm{C}$ for $30 \mathrm{~min}$. Reaction products were precipitated with ethanol and washed to remove the bulk of the unincorporated mucleotides. Specific activities of $25 \times 10^{6}$ to $45 \times 10^{6} \mathrm{cpm} / \mu \mathrm{g}$ were obtained routinely. The probes labeled were: Spec1-M13mp19 containing the 1.05-kb SstI-XbaI fragment of Specla cDNA (Carpenter 1984), used as a negative control in deciliation experiments; Spec3-M13mp19 containing the $1.03-\mathrm{kb}$ EcoRI-Xbal fragment of the kappa cDNA clone (Fig. 5); and mitichondrial $16 S$ rRNA-M13mp8 containing a 550-bp EcoRI fragment of the $S$. purpuratus mitochondrial 16S rRNA (Wells et al. 1982), used to standardize the amount of hybridizable RNA on the filters.

\section{Random oligonucleotide-primer labeling of $\beta$-tubulin cDNA}

The method of Feinberg and Volgelstein (1983) was used to label a gel-purified 365-bp BamHI-BglII fragment from the coding region of the $\beta_{1}$-tubulin cDNA clone J1-pUC19-365-5 (a gift from $P$. Harlow and $M$. Nemer) to a specific activity of $1.6 \times 10^{8} \mathrm{cpm} / \mu \mathrm{g}$. Labeled fragments were ethanol-precipitated and washed to removed the bulk of the unincorporated nucleotides.

\section{RNA accumulation during normal development}

RNA was isolated from eggs and embryos every $4 \mathrm{hr}$ from 3 to $59 \mathrm{hr}$ and every $6 \mathrm{hr}$ from 65 to $107 \mathrm{hr}$ from synchronously growing cultures of $S$. purpuratus embryos by the guanidine$\mathrm{HCl}$ method described by Bruskin et al. (1981). Ten-microgram samples were electrophoresed on formaldehyde agarose gels (Bruskin et al. 1981) and blotted to nitrocellulose. Blots were hybridized with an M13 single-stranded probe of the EcoRI$X b a I$ fragment of the Spec 3 cDNA probe that included the entire open reading frame and $108 \mathrm{bp}$ of $5^{\prime}$ untranslated sequence and 287 bp of 3 ' untranslated sequence (Fig. 5). Prehybridization and hybridization reactions were carried out as previously described (Bruskin et al. 1981). Final wash conditions were $68^{\circ} \mathrm{C}$ in $0.066 \mathrm{M} \mathrm{Na}^{+}$for $1-2 \mathrm{hr}$, unless otherwise indicated. Signals were quantified by densitometric scanning of several autoradiographic exposures of the RNA blot to insure linearity. To standardize the amount of hybridizable RNA in each lane, the filter was probed with the 550-bp EcoRI fragment of the mito- chondrial 16S rRNA sequence described above. Accumulation was plotted as a proportion of maximal level reached during development.

\section{In situ hybridization}

A 1.74-kb Spec3 cDNA fragment bounded by EcoRI restriction sites (Fig. 5) was inserted into two different vectors, each containing an Sp6 promoter. The insert in pSp6Z1 (Angerer et al. 1985) contains two of the Spec3 sequences in the same orientation, whereas, that in pSp65 is a monomer. Run-off transcripts [3900 nucleotides (pSpZ1) or 1790 nucleotides (pSp65)] were synthesized from HindIII-digested templates as described previously (Lynn et al. 1983). Sister constructions provided comparable sense strand transcripts for use as controls for nonspecific background binding of probe. Similarly, a 1.3-kb PstI cDNA fragment containing $\beta$-tubulin sequence (blast $j 1$, kindly provided by $M$. Nemer) was transferred to pSp64 and pSp65 for preparation of sense and antisense RNA probes with Sp6 RNA polymerase. The specific activity of the run-off transcripts was adjusted to $0.91 \times 10^{8}$ to $1.1 \times 10^{8} \mathrm{dpm} / \mu \mathrm{g}$ using $\left[{ }^{3} \mathrm{H}\right] \mathrm{CTP}$ and $\left[{ }^{3} \mathrm{H}\right]$ UTP (Amersham). Methods for purification and reduction of the fragment length of probes to $150-200$ bases, for glutaraldehyde fixation and prehybridization treatments of tissue and for in situ hybridization have been described previously (Angerer and Angerer 1981; Cox et al. 1984). Hybridizations were done at $45^{\circ} \mathrm{C}$ using saturating probe concentrations of $0.5-1$ $\mu \mathrm{g} / \mathrm{ml}$, and autoradiographic exposure times were 28-31 days.

\section{RNA accumulation following deciliation}

Gastrula-stage embryos were deciliated by stirring $2 \mathrm{~min}$ in hypertonic seawater, following the protocol of Stephens (1986). Following deciliation, the embryos were washed once in artificial seawater and cultured at $14^{\circ} \mathrm{C}$ with constant stirring. A portion of the culture was harvested every $15 \mathrm{~min}$ for $2 \mathrm{hr}$ and RNA was isolated by rapid lysis in a buffer containing $50 \mathrm{~mm}$ HEPES ( $\mathrm{pH} 8.0$ ), $0.5 \mathrm{M}$ sodium acetate $(\mathrm{pH} 6.0)$, $2 \%$ sodium dodecyl sulfate, and $1 \%$ diethyl pyrocarbonate. The preparation was extracted once with phenol and once with chloroform and then precipitated with ethanol. The resulting pellet was resuspended in $3.0 \mathrm{M}$ sodium acetate (pH 6.0), and RNA was allowed to precipitate at $-20^{\circ} \mathrm{C}$ overnight (Palmiter 1974). Equal amounts of total RNA were denatured for electrophoresis and loaded onto nylon membrane filters (Hybond-N, Amersham) using a dot-blot apparatus (BioRad). Quadruplicate filters were made and hybridized as described in Results, using the conditions described above for filter hybridization. The amount of probe hybridized to each filter was determined in a scintillation counter. The amount of total RNA on each dot was determined using the mitochondrial 16S rRNA probe as a standard. Accumulation was plotted as a fraction of the maximum level reached over the course of the experiment.

\section{Mapping the initiation of trascription}

One nanogram of a synthetic 20-base oligonucleotide complementary to the first 20 nucleotides of the putative protein coding sequence was labeled at the $5^{\prime}$ end using polynucleotide kinase and hybridized with $50 \mu \mathrm{g}$ of total blastula RNA for $2 \mathrm{hr}$ at $15^{\circ} \mathrm{C}$ below the calculated $T_{\mathrm{m}}$. The oligonucleotide primer was extended using AMV reverse trancriptase (Life Sciences) in the presence of $8 \mathrm{nM}$ dNTPs. To determine the sequence of the extended product and identify the nucleotide with which transcription inititates, the synthetic 20 -base oligonucleotide was used to prime chain-termination sequencing reactions from the appropriate genomic template. The products of the extension and sequencing reactions were resolved on the same $6 \%$ denaturing acrylamide gel cast in a buffer gradient. 
Isolation of genomic clones

A $\lambda E M B L 3$ library, made with one male sea urchin's genomic DNA partially digested with Sau3A, was screened with the 1.4$\mathrm{kb}$ EcoRI-BamHI fragment of the Spec3-kappa cDNA clone, which had been radioactively labeled by nick translation. Phages producing positive plaques were purified, and DNA was isolated using standard procedures outlined by Maniatis et al. (1982).

\section{DNA sequencing reactions}

Restriction fragments labeled at a unique end were chemically degraded by the method of Maxam and Gilbert (1980) as modified by Bencini et al. (1984). Reaction products were electrophoresed on $8 \%$ and $20 \%$ denaturing polyacrylamide gels (Sanger and Coulson 1978).

Fragments subcloned into M13 were sequenced by the chaintermination method of Sanger et al. (1977). The chain-termination method as modified by Chen and Seeburg (1985) was employed to sequence double-stranded plasmids. Reaction products were separated on denaturing polyacrylamide gels cast in a buffer gradient (Biggin et al. 1983).

\section{Genomic DNA blots}

Ten micrograms of DNA isolated from the sperm of a single urchin was digested with restriction enzymes and electrophoresed on $0.8 \%$ neutral agarose gels and blotted onto nitrocellulose (Southern 1975). Blots were hybridized as described by Bruskin et al. (1981). Final wash conditions were $0.06 \mathrm{M} \mathrm{Na}^{+}$at $68^{\circ} \mathrm{C}$, unless otherwise indicated.

\section{Acknowledgments}

We thank Kathy Oleszkowicz and Sue Kozak for technical assistance, Jim White for the protein sequence homology search, Francesa Pignoni for help with analysis of the genomic clones, Terry Matthews for assistance with figure preparation, and Gertrude Willis for secretarial assistance. We are grateful to $\mathrm{M}$. Nemer for providing the blast $\mathrm{jl}$ cDNA clone prior to its identification by Harlow et al. (1988). This work was supported by National Institutes of Health grants HD-R01-22619 to W.H.K. and GM-R01-25553 to R.C.A., W.H.K. and R.C.A. are recipients of NIH Research Career Development Awards HD735 and HD601, respectively.

\section{Note added in proof}

The blast J1 $\beta$-tubulin clone has been sequenced recently by $P$. Harlow, S. Litwin, and M. Nemer (J. Mol. Evol. 26: in press). It contains open reading frame sequences, which hybridize to all $\beta$-tubulin messages and $3^{\prime}$ untranslated sequences, which hybridize only to $\beta_{1}$-tubulin transcripts.

\section{References}

Alexandraki, D. and J. Ruderman. 1983. Evolution of $\alpha$ and $\beta$ tubulin genes as inferred by nucleotide sequence of sea urchin cDNA clones. J. Mol. Evol. 19: 397-410.

. 1985. Expression of $\alpha$ amd $\beta$-tubulin genes during development of sea urchin embryos. Dev. Biol. 109: 436-451.

Angerer, L.M. and R.C. Angerer. 1981. Detection of poly $(A)^{+}$ RNA in sea urchin eggs and embryos by quantitative in situ hybridization. Nucleic Acids Res. 9: 2819-2840.
Angerer, R.C., K.H. Cox, and L.M. Angerer. 1985. In situ hybridization to cellular RNAs. Genet. Eng. Lett. 7: 43-65.

Baker, E.J., J.A. Schloss, and J.L. Rosenbaum. 1984. Rapid changes in tubulin RNA synthesis and stability induced by deflagellation in Chlamydomonas. I. Cell Biol. 99: 20742081.

Bedard, P.-A. and B.P. Brandhorst. 1983. Patterns of protein synthesis and metabolism during sea urchin embryogenesis. Dev. Biol. 96: 74-83.

Bencini, D.A., G.A. O'Donovan, and J.R. Wild. 1984. Rapid chemical degradation sequencing. Biotechniques 2: 4-5.

Benson, S., H.M. Sucov, L. Stephens, E.H. Davidson, and F. Wilt. 1987. A lineage specific gene encoding a major matrix protein of the sea unchin embryo spicule. I. Authentication of the cloned gene and its developmenetal expression. Dev. Biol. 120: 499-506.

Biggin, M.D., T.J. Gibson, and G.F. Hong. 1983. Buffer gradient gels and ${ }^{35} \mathrm{~S}$ label as an aid to rapid DNA sequence determination. Proc. Natl. Acad. Sci. 80: 3963-3965.

Bruskin, A.M., A.L. Tyner, D.E. Wells, R.M. Showman, and W.H. Klein. 1981. Accumulation in embryogenesis of five mRNAs enriched in the ectoderm of the sea urchin pluteus. Dev. Biol. 87: 308-318.

Bruskin, A.M., P.-A. Bedard, A.L. Tyner, R.M. Showman, B.P. Brandhorst, and W.H. Klein. 1982. A family of proteins accumulating in ectoderm of sea urchin embryos specified by two related cDNA clones. Dev. Biol. 92: 317-324.

Burns, R.G. 1973. Kinetics of regeneration of sea urchin cilia. J. Cell Sci. 13: 55-67.

Carpenter, C.D. 1984. "The messages and genes encoding calcium-binding proteins in the embryonic ectoderm of the sea urchin." PhD. thesis, Indiana University, Bloomington, Indiana.

Carpenter, C.D., A.M. Bruskin, P.E. Hardin, M.J. Keast, J. Anstrom, A.L. Tyner, B.P. Brandhorst, and W.H. Klein. 1984. Novel proteins belonging to the troponin $\mathrm{C}$ superfamily are encoded by a set of mRNA is sea urchin embryos. Cell 36: 663-671.

Chen, E.Y. and P.H. Seeburg. 1985. Supercoil sequencing: A fast and simple method for sequencing plasmid DNA. DNA 4: $165-170$.

Cleveland, D.W., M.A. Lopata, P. Sherline, and M.W. Kirschner. 1981. Unpolymerized tubulin modulates the level of tubulin mRNAs. Cell 25: 537-546.

Cox, K.H., D.V. DeLeon, L.M. Angerer, and R.C. Angerer. 1984. Detection of mRNAs in sea urchin embryos by in situ hybridization using asymmetric RNA probes. Dev. Biol. 101: 485-502.

Cox, K.H., L.M. Angerer, J.J. Lee, E.H. Davidson, and R.C. Angerer. 1986. Cell lineage-specific programs of expression of multiple actin genes during sea urchin embryogenesis. $I$. Mol. Biol. 188: 159-172.

Davidson, E.H. 1986. Gene activity in early development, 3rd ed., pp. 229-233. Academic Press, Orlando, Florida.

Eldon, E.D. 1988. "A gene and its protein product involved in embryonic ectodermal ciliogenesis in the sea urchin." Ph.D. thesis, Indiana University, Bloomington, Indiana.

Feinberg, A.P. and B. Volgelstein. 1983. A technique for radiolabeling DNA restriction endonuclease fragments to high specific activity. Anal. Biochem. 132: 6-13.

Gibson, A.W. and R.D. Burke. 1985. The origin of pigment cells in embryos of the sea urchin Strongylocentrotus purpuratus. Dev. Biol. 107: 414-419.

Gong, Z. and B.P. Brandhorst. 1987. Stimulation of tubulin gene transcription by deciliation of sea urchin embryos. Mol. Cell. Biol., (in press). 
Harlow, P. and M. Nemer. 1987a. Developmental and tissuespecific regulation of $\beta$ tubulin gene expression in the embryo of the sea urchin Strongylocentrotus purpuratus. Genes Dev. 1: $147-160$.

-1987b. Coordinate and selective $\beta$ tubulin gene expression associated with cilium formation in sea urchin embryos. Genes Dev. 1: 1293-1304.

Harlow, P., S. Litwin, and M. Nemer. 1988. Synonymous nucleotide substitution rates of $\beta$-tubulin and genomic rates in rodents but not in sea urchins. J. Mol. Evol. 26: (in press).

Kemphues, K.J., T.C. Kaufman, R.A. Raff, and E.C. Raff. 1982. The testis-specific $\beta$-tubulin subunit in Drosophila melanogaster has multiple functions in spermatogenesis. Cell 31: 665-670.

Kyte, J. and R. Doolottle. 1982. A simple method for displaying the hydropathic character of a protein. I. Mol. Biol. 157: 105-132.

Leaf, D.S., J.A. Anstrom, J.E. Chin, M.A. Harkey, R.M. Showman, and R.A. Raff. 1987. Antibodies to a fusion protein identify a cDNA clone encoding msp130, a primary mesenchyme specific cell surface protein of the sea urchin embryo. Dev. Biol. 121: 29-40.

Lee, J.J., F.J. Calzone, R.J. Britten, R.C. Angerer, and E.H. Davidson. 1986. Activation of sea urchin actin genes during embryogenesis: Measurement of transcript accumulation from five different genes in Strongylocentrotus purpuratus. J. Mol. Biol. 188: 173-183.

Lefebvre, P.A., C.D. Silflow, E.D. Weinben, and J.L. Rosenbaum. 1980. Increased levels of mRNAs for tubulin and other flagellar proteins after amputation or shortening Chlamydomonas flagella. Cell 20: 469-477.

Lynn, D.A., L.M. Angerer, A.M. Bruskin, W.H. Klein, and R.C. Angerer. 1983. Localization of a family of mRNAs in a single cell type and its precursor in the sea urchin embryo. Proc. Natl. Acad. Sci. 80: 2656-2660.

Maniatis, T., E.F. Fritsch, and J. Sambrook. 1982. Molecular cloning: A laboratory manual. Cold Spring Harbor Laboratory, Cold Spring Harbor, New York.

Maxam, A.M. and W. Gilbert. 1980. Sequencing end-labeled DNA with base- specific chemical cleavage. Methods Enzymol. 65: 499-559.

Maxson, R.E. and F.H. Wilt. 1982. Accumulation of the early histone messenger RNAs during the development of Strongylocentrotus purpuratus. Dev. Biol. 94: 435-440.

McClay, D.R. 1986. Embryo dissociation, cell isolation and cell reassociation. In Methods in cell biology: Echinoderm gametes and embryos (ed. T.E. Schroeder), vol. 27, pp. 309-323. Academic, New York.

Merlino, G.T., J.P. Chamberlain, and L.J. Kleinsmith. 1978. Effects of deciliation on tubulin messenger RNA activity in sea urchin embryos. J. Biol. Chem. 253: 7078-7085.

Mitchell, D.R. and J.L. Rosenbaum. 1985. A motile Chlamydomonas flagellar mutant that lacks outer dynein arms. J. Cell Biol. 100: 1229-1234.

Mohun, T., R.E. Maxson, G. Gormezano, and L. Kedes. 1985. Differential regulation of individual late histone genes during development of the sea urchin (Stronglyocentrotus purpuratus). Dev. Biol. 108: 491-502.

Morrill, J.B. and L.L. Santos. 1985. A scanning electron microscopical overview of cellular and extracellular patterns during blastulation and gastrulation in the sea urchin, Lytechinus variegatus. In The cellular and molecular biology of invertebrate development led. R.H. Sawyer and R.M. Showman), pp. 3-33. University of South Carolina, Columbia, South Carolina.
Nemer, M. 1986. An altered series of ectodermal gene expression accompanying the reversible suspension of differentiation in the zinc-animalized sea urchin embryo. Dev. Biol. 114: $214-224$.

Palmiter, R.D. 1974. Magnesium precipitation of ribonucleoprotein complexes. Expedient techniques for the isolation of undegraded polysomes and messenger ribonucleic acid. Biochemistry 13: 3606-3615.

Pehrson, J.R. and L.H. Cohen. 1986. The fate of the small micromeres in sea urchin development. Dev. Biol. 113: 522526.

Piperno, G., B. Huang, and D.J.L. Luck. 1977. Two-dimensional analysis of flagellar proteins from wild type and paralyzed mutants of Chlamydomonas reinhardtii. Proc. Natl. Acad. Sci. 74: 1600-1604.

Piperno, G., B. Huang, Z. Ramanis, and D.L. Luck. 1981. Radial spokes of Chlamydomonas flagella: Polypeptide composition and phosophorylation of stalk components. J. Cell Biol. 88: $75-79$.

Riederer-Henderson, M.A. and J.L. Rosenbaum. 1979. Ciliary elongation in blastulae of Arbacia punctulata induced by trypsin. Dev. Biol. 70: 500-509.

Sanger, F. and A.R. Coulson. 1978. The use of thin acrylamide gels for DNA sequencing. DNA 4: 164-170.

Sanger, F., S. Nicklen, and A.R. Coulson. 1977. DNA sequencing with chain terminating inhibitors. Proc. Natl. Acad. Sci. 74: 5643-5647.

Schloss, J.A., C.D. Silflow, and J.L. Rosenbaum. 1984. mRNA abundance changes during flagellar regeneration in Chlamydomonas reinhardtii. Mol. Cell. Biol. 4: 424-434.

Shepherd, G.W., E. Rondenelli, and M. Nemer. 1983. Differences in abundance of individual RNAs in normal and animalized sea urchin embryos. Dev. Biol. 96: 520-527.

Southern, E.M. 1975. Detection of specific sequences among DNA fragments separated by gel electrophoresis. I. Mol. Biol. 98: 503-517.

Stephens, R.E. 1977. Differential protein synthesis and utilization during cilia formation in sea urchin embryos. Dev. Biol. 61: 311-329.

. 1986. Isolation of embryonic cilia and sperm flagella. In Methods in cell biology: Echinoderm gametes and embryos (ed. T.E. Schroeter), vol. 27, pp. 217-227. Academic Press, New York.

Wells, D.E., A.M. Bruskin, D.A. O'Brochta, and R.A. Raff. 1982. Prevalent RNA sequence of mitochondrial origin in sea urchin embryos. Dev. Biol. 92: 557-562.

Wessel, G.M. and D.R. McClay. 1985. Sequential expression of germ-layer specific molecules in the sea urchin embryo. Dev. Biol. 111: 451-463.

1987. Gastrulation in the sea urchin embyro requires the deposition of crosslinked collagen within the extracellular matrix. Dev. Biol. 121: 149-165.

Wessel, G.M., R.B. Marchase, and D.R. McClay. 1984. Ontogeny of the basal lamina in the sea urchin embryo. Dev. Biol. 103: 235-245.

Wickner, W.T. and H.F. Lodish. 1985. Multiple mechanisms of protein insertion into and across membranes. Science 230: $400-407$.

Wilkinson, D.G. and M. Nemer. 1987. Metallothionein gene MTa and MTb expressed under distinct quantitative and tissue-specific regulation in sea urchin embryos. Mol. Cell. Biol. 7: 48-58.

Williams, B.D., D.R. Mitchell, and J.L. Rosenbaum. 1986. Molecular cloning and expression of flagellar radial spoke and dynein genes of Chlamydomonas. J. Cell. Biol. 103: 1-11. 


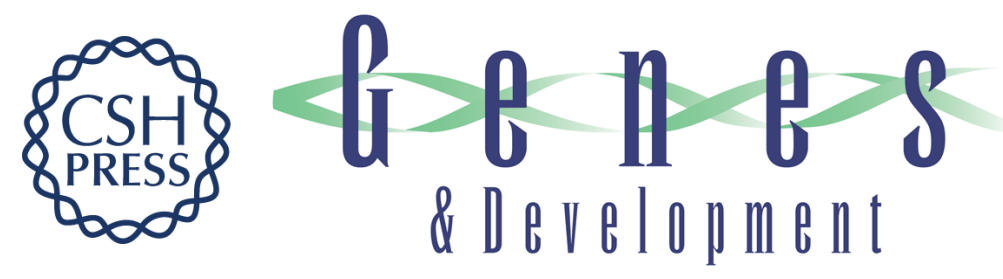

\section{Spec3: embryonic expression of a sea urchin gene whose product is involved in ectodermal ciliogenesis.}

E D Eldon, L M Angerer, R C Angerer, et al.

Genes Dev. 1987, 1:

Access the most recent version at doi:10.1101/gad.1.10.1280

References This article cites 51 articles, 12 of which can be accessed free at: http://genesdev.cshlp.org/content/1/10/1280.full.html\#ref-list-1

License

Email Alerting Receive free email alerts when new articles cite this article - sign up in the box at the top Service right corner of the article or click here.

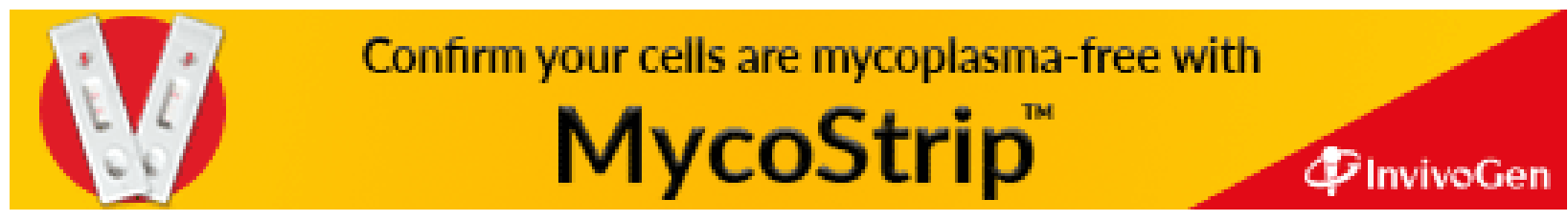

